\title{
PREFACE
}

\section{Preface to the focus theme on eCRM}

\author{
Nicholas C. Romano Jr. • Jerry L. Fjermestad
}

Published online: 17 July 2009

(C) Institute of Information Management, University of St. Gallen 2009

This Focus theme section of Electronic Markets on Electronic Customer Relationship Management (eCRM) focuses on the critical aspect of customers in ecommerce. Commerce in electronic markets (eCommerce) remains a significant, pervasive phenomenon for enterprises, customers, governments and consumer advocacy watchdogs. Three important relationships in electronic markets include: between enterprises and customers (B2C); among enterprises (B2B); and among customers (C2C). Additional relationships between governments $(\mathrm{G} 2 \mathrm{G})$, enterprises (G2B) and customers (G2C) become more important as electronic markets and eGovernment mature and legislation, regulation and oversight increase. Fundamentally eCRM (from the customer's perspective) concerns attracting and keeping "Economically Valuable" customers and repelling and eliminating "Economically Invaluable" ones. Electronic markets are evolving from "first order" transactional value exchanges through "second-order" informational value exchanges into "third-order" relational value exchanges. These relational value exchanges are central to success and competitive advantage for firms and customers that engage in eCommerce. This focus theme addresses those value exchanges between customers and enterprises.

The concept of CRM in the Information Systems (IS) Discipline can be traced back to early ideas that

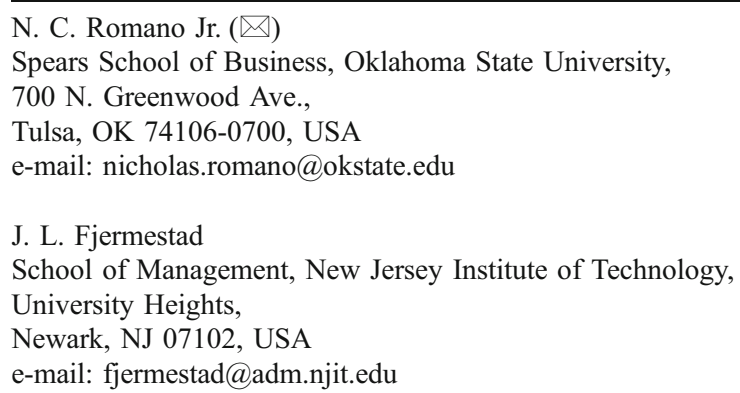

customers should be considered as assets, sources of value and resources to be managed across a lifecycle (Ives and Learmonth 1984; Ives and Mason 1990.) More specifically Ives and Learmonth proposed the IS Customer Resource Life Cycle and later Ives and Mason (Ives and Mason 1990) explained how IS can revitalize customer service. However these early forays into "CRM" were not followed in the literature by any substantial set of published articles, let alone by practice in the IS field.

Such visionary articles often precede mainstream research and practice. This is not to say that there were not articles on CRM published in other disciplines, particularly Marketing, before or contemporaneously with these two foundational IS articles, but rather that these were the first we found in an extensive literature review of IS-CRM (Romano and Fjermestad 2001-2002).

In our introspective study of IS-CRM (Romano and Fjermestad 2001-2002) we made six recommendations that would indicate maturation of CRM as an MIS subfield of study as follows: One, development of empirically testable CRM theories; Two, conducting of lab and field experiments to test hypotheses based on theory; Three, development and use of valid instruments; Four, development of a cumulative tradition of research and replication, extension of theories, models, and instruments, and development of standard constructs and metrics; Five, additional publication of ISCRM research in top MIS journals; and Six, development of new classification schemes for rapidly changing terminology.

In this Focus Theme section although there are only two articles, both contribute to the maturity of CRM in IS research. The first paper develops and tests two "contingency" hypotheses with Moderated Regression Analysis (MRA). The authors also rigorously validated their instrument. This article is a clear example of the maturation of the research questions, theory development, 
instrument validation, and analysis methodology that have taken place in the IS CRM literature over the past decade. The second paper thoroughly develops and tests a detailed theoretically grounded research model through a laboratory experiment. The authors also employed Partial Least Squares (PLS) to validate and analyze their model. This article also illustrates the maturation of CRM research through theory development, experimentation and rigorous validation and analysis. Both papers also build on previous literature streams and thus extend the cumulative tradition of IS research. Next we summarize each of the articles in the focus theme section.

The first paper Collaborative e Product Development and Product Innovation in a Demand Driven Network: The Moderating role of eCRM by Pierre Hadaya, and Luc Cassivi discuss a unique integration of eCRM and product development. Hadaya and Cassivi's basic eCRM model consists of eCRM adoption, investments in eCRM implementation, and internal integration of eCRM. A survey instrument is used in the wireless communication equipment sector from six countries from Scandinavia and North America. The firms were selected based on tightly coupled demand-driven networks that encourage interorganizational collaboration between members, and a high level of electronic commerce penetration. One-hundred and four questionnaires were completed.

The results demonstrate that within a demand-driven network, collaborative e-product development between the manufacturer and its key customers is critical to improving the manufacturer's own product innovation. Another interesting result is that by merely adopting an IS technology, eCRM, for example, cannot generate positive performance outcomes within or among the various functions of the extended enterprise unless it is combined with efforts to assimilate the technology. There findings show that significant investments in eCRM implementation can strengthen the impact of collaborative e-product development between a manufacturer and its customers on product innovation within the manufacturer itself. Furthermore, the implementation phase of eCRM is so important that it is most often cited as the make or break phase for the assimilation of a technology. Lastly, the authors emphasize the importance of making good use of the eCRM to strengthen the impact of collaborative e-product development between a manufacturer and its customers on product innovation within the manufacturer.

The authors also discuss three important theoretical contributions. First, this paper is among the few empirical studies to have investigated the impact of eCRMs on product development practices. Second, it is also one of the few to use a contingency approach in the context of adoption, implementation and usage of eCRM. Finally, their study demonstrates that a eCRM can directly impact product innovation in a demanddriven network. They suggest that these three contributions will also be of interest to management.

The second paper "The Impact of Uncertainty Avoidance, Social Norms and Innovativeness on Trust and Ease of Use in Electronic Customer Relationship Management" by Yujong Hwang examines the influences of social and individual factors on online trust in eCRM. Hwang, in this paper, tests the relationships among uncertainty avoidance, social norms, personal innovativeness in IT, and multidimensions of online trust (integrity, benevolence, and ability) as well as perceived ease of use.

An experiment was conducted with 209 students in an Internet classroom. The students were asked to navigate www.amazon.com, and go through the procedure of purchasing a book without actually submitting the purchase transaction and then complete an on-line survey.

The results of the study reveal three primary findings. First, uncertainty avoidance influences only the benevolence and ability dimensions of online trust. This suggests that to increase the integrity dimension of online trust, IS designers should emphasize the social normative aspects of a website (such as feedback mechanisms in the online community or media) rather than reducing procedural uncertainty by formal rules of conduct listed on the website. Also, trust beliefs of the website should be enhanced through the perception that the target website is easy to use even in the case of innovative and proactive IT.

The two papers in this Focus theme on eCRM illustrate both a maturing of IS-CRM research and a focus on collaborative and value-exchange aspects in electronic markets. While we are disappointed that only two papers were accepted for publication in this focus theme, we are also encouraged by both the rigor and relevance they both exemplify. CRM in IS has matured and in fact we now believe that there is a movement toward the more holistic concept of collaborative commerce, in which relationships among and between enterprises, customers and governments all can help achieve value through transactional, information and relational exchanges.

\section{References}

Ives, B., \& Learmonth, G. P. (1984). he Information System as a Competitive Weapon. Comunications of the ACM, 27(12), 1193-1201.

Ives, B., \& Mason, R. O. (1990). Can information technology revitalize your customer service? Academy of Management Executive, 4(4), 52-69.

Romano, N. C., Jr., \& Fjermestad, J. (2001-2002). Customer Relationship Management Research: An Assessment of Research. International Journal of Electronic Commerce, 6(3), 61-114. 